\title{
The possible Protective role of alpha-lipoic acid on nanosilver particle-induced hepatotoxicity in male rats
}

Eman M. Abd Elmaksoud*, Nabil M.Taha*, Mohamed A. Lebda*, Aml E. Hashem*, Maher A. Kamel\# *Department of Biochemistry, Faculty of Veterinary medicine, Alexandria University, Egypt.

${ }^{\#}$ Department of Biochemistry, Medical Research Institute, Alexandria University, Egypt.

\begin{tabular}{|c|c|}
\hline ARTICLE INFO & ABSTRACT \\
\hline $\begin{array}{l}\text { Keywords: } \\
\text { Silver nanoparticles, } \alpha \text {-Lipoic acid, } \\
\text { Hepatotoxicity, Oxidative stress, } \\
\text { Mitocondrial dysfunction. } \\
\text { Abbreviations } \\
\text { AgNPs; Silver nanoparticles, LA; , } \alpha \text { - } \\
\text { Lipoic acid }\end{array}$ & $\begin{array}{l}\text { Objective: This study aimed to explore the hepatotoxicity induced by } \\
\text { silver nanoparticles (AgNPs) and to assess the hepatoprotective } \\
\text { effects of } \alpha \text {-lipoic acid (LA) against this toxicity. Methods: Thirty } \\
\text { adult male rats were enrolled into } 3 \text { equal groups; Control, AgNPs } \\
(50 \mathrm{mg} / \mathrm{kg} / \mathrm{i} . \mathrm{P} \text { ) and LA ( } 100 \mathrm{mg} / \mathrm{kg} / \text { orally) +AgNPs. After } 30 \text { days, } \\
\text { blood and liver tissues were collected for further studies. Results: } \\
\text { AgNPs exposure enhanced lipid peroxidation }(+281.7 \% \text { ) along with } \\
\text { declines in glutathione (-58.3\%) Level in hepatic tissues. The } \\
\text { apparent hepatic oxidative damage was associated with obvious } \\
\text { hepatic dysfunction that was ascertained by hepatopathological } \\
\text { lesions.As, following AgNPs exposure, hepatic silver content and } \\
\text { serum ALT, AST and ALP activities were increased, moreover } \\
\text { allows calcium influx and induces intracellular calcium overload. } \\
\text { Hepatic tissues treated with AgNPs showed down-regulation of all } \\
\text { the genes considered (PGC-1 } \alpha \text {, Tfam and Nrf2).LA improved the } \\
\text { serious effects of AgNPs on the liver tissues through its antioxidant } \\
\text { andmetal chelator efficacy. Conclusion: Silver nanoparticles } \\
\text { (AgNPs) can induce hepatotoxicity along with oxidative stress, } \\
\text { substantial decrease in cell viability with concomitant increases in } \\
\text { DNA damage. Oral treatment with LA effectively counteracted the } \\
\text { adverse effects of AgNPs. }\end{array}$ \\
\hline
\end{tabular}

\section{Introduction:}

Silver nanoparticles (AgNPs) have been broadly used in various commercial products including wound dressings, drugs, cosmetics, bedding, water purification, washing machines, deodorants, humidifierstextiles, electronic appliances and biomedical products due to their strong antibacterial activity [1]. AgNPs can enter the body through different routes as inhalation, injection, ingestion, and dermal contact, resulting in a dosedependent increase of silver concentration in various organs [2]. Moreover, AgNPs have a toxic effect in their persistence. So, the concerns have been higher on the potential risk of using nanoparticles in medical applications [3]. Most AgNPswere found to accumulate in the liver, a major organ of detoxification. Their excessive accumulation in the liver caused various adverse effects including pathological changes in liver morphology, inflammatory cell infiltration, bile-duct hyperplasia, apoptosis and necrosis [4]. AgNPs are known to induce generation of reactive oxygen species (ROS) in various cell types [5].The harmful effects of include oxidative DNA damage, oxidations of amino acids in proteins, oxidations of polyunsaturated fatty acids in lipids [6],depletion of glutathione and changes in the activity 
of several antioxidant enzymes [7]. Mitochondria appear to be the sensitive target for AgNPs which accumulate outside the mitochondria of the cell, cause direct mitochondrial damage, and disturb the function of the respiratory chain, resulting in ROS generation and oxidative stress [8]. PGC-1aconsidered as the 'master regulator' of mitochondrial biogenesis, which improves the expression of nuclear genes encoding mitochondrial proteins [9], also distributed inside mitochondria where it forms a multiprotein complex with mitochondrial transcribtion factor $\mathrm{A}$ (mTFA) on mtDNA [10]. PGC- $1 \alpha$ is the 'master regulator' of mitochondrial biogenesis, which improves the expression of nuclear genes encoding mitochondrial proteins [9], also forms a multiprotein complex with mitochondrial transcription factor A (mTFA) on mtDNA [10]. mtTFA is a nuclear-encoded factor that promotes mtDNA transcription and expression [11], increases mtDNA copy number [12], protects and repairs damaged mtDNA and restores mitochondrial function [13].

$\alpha$-lipoic acid (LA) also known as thioctic acid is an organosulfur compound derived from octanoic acid [14]. LA is synthesized in the hepatic tissue and other tissues to a sufficient extent, for its role as an enzyme cofactor in intermediary metabolism. Moreover, LA has been considered as a therapeutic agent in a number of conditions related to liver disease, including alcohol-induced damage, hyperdynamic circulation in biliary cirrhosis and metal intoxication [15]. LA is a potent antioxidant. So, it and its reduced dithiol form dihydrolipoic acid (DHLA), acting as biological antioxidants, metal chelators (such as $\mathrm{Fe}^{2+}, \mathrm{Cu}^{2+}$ and $\mathrm{Cd}^{2+)}[16]$, reducing the oxidized forms of antioxidant agents such as vitamin $\mathrm{C}$ and $\mathrm{E}$ and glutathione (GSH) [17]. LA is an activator of translocation of nuclear factor erythroid 2-related factor (Nrf2) to the nucleus for regulation of antioxidant gene expression [18]. Nrf2 can play a significant role in the attenuation of oxidative stress through the suppression of pro-inflammatory signaling pathways [19]. The antioxidant effect of LA resulting in a lower level of DNA damage and improved activities of the indicators of hepatocellular injury, alanine aminotransferase (ALT) and aspartate aminotransferase (AST), suggesting that LA exerted hepatoprotective effects in diabetes[20].

This study aimed to explore the hepatotoxicity induced by silver nanoparticles (AgNPs) and to assess the hepatoprotective effects of $\alpha$-lipoic acid (LA) against this toxicity.

\section{Materials and Methods: Chemicals and Reagents}

AgNPs powder was purchased from Sigma-Aldrich (St. Louis, MO,USA). The particles were suspended in deionized water by vigorousvortexing and sonication prior to use to ensure the prevention of particle aggregation. LA was obtained from (NATROL, Inc. Chatsworth, USA). HNO3and $\mathrm{HCl}$ were purchased from (Sigma-Aldrich). Kits for ALT, AST, ALP, Total protein, Albumin, Triacylglycerol, Total cholesterol,HDLc, total and direct bilirubin were purchased from vitro,Science Co., Egypt.

\section{Nanoparticles characterization}

The morphology and the particle size of AgNPs were examined bytransmission electron microscope (TEM) [21]. Briefly, AgNPs powder was suspended in deionized water (2 $\mathrm{mg} / \mathrm{mL}$ ). A drop of this solution was deposited on an amorphous carbon coated copper grid, which left to 
evaporate at room temperature forming a monolayer. Analysis of the particle size diameter of the prepared AgNPs was estimated using the software program image $\mathbf{J}$ over several shots of TEM images.

\section{Experimental Design}

Thirty male Wistar Albino rats weighing $150 \pm 20 \mathrm{~g}$ were purchasedfrom Animal Breeding Unit, Medical Research Institute, Alexandria University. The animals were kept in metal cages under environmental controlled conditions with optimum temperature, humidity, and dark/light cycle and free access to rat chow and drinking water. The international ethical guidelines for the care and use of laboratory animals were performed to handle the animals and the experimental procedures were approved by the Experimental Animal Use and Ethics Committee at the Faculty of Veterinary Medicine, Alexandria University, Egypt.The rats were randomly assigned to three groups (10 rats each); control, AgNPsintoxicated group intraperitoneally injected with AgNPs 50 mg/kgb.w., 3 times a week [22], LA+AgNPs group intoxicated with AgNPs and orally gavaged with $100 \mathrm{mg} \mathrm{LA} / \mathrm{kg}$ b.w. [23]. All treatments were continued for 30 consecutive days. Twenty-four hours after the last doses, the rats were anesthetized using ketamine/xylazine $(7.5-10 \mathrm{mg} / \mathrm{kg}, 1 \mathrm{mg} / \mathrm{kg}$ i.p). The blood was collected from the innercanthus, and the sera were separated for estimation of alanine aminotransferase (ALT), aspartate aminotransferase (AST), akaline phosphatase (ALP), total protein, albumin, total and direct bilirubin, triglycerides (TG), total cholesterol and high density lipoprotein cholesterol (HDL-c). The rats were then euthanized and the liver were immediately dissected, rinsed with chilled normal saline $0.9 \%$ and divided into three parts; first one was used for gene expression of Nrf2, PGC-1 $\alpha$ and mTFA and the second part was used for estimation of $\mathrm{Ag}$, trace elements and finally third part was used for oxidative indices.

Estimation of silver, iron, copper, $\mathrm{Ca}$ and $\mathrm{Zn}$ contents

About $1 \mathrm{~g}$ of liver tissue was ashed at $600{ }^{\circ} \mathrm{C}$, the ash was digested with acid mixture solution ( $\mathrm{HNO} 3$ and $\mathrm{HCl}$ )then all samples were filtered, and diluted. Liver content of $\mathrm{Ag}^{+}, \mathrm{Fe}^{2+}$, $\mathrm{Ca}^{2+}, \mathrm{Cu}^{2+}$ and $\mathrm{Zn}^{2+}$ were quantitatively measured by Inductively Coupled Plasma Mass Spectrometry (ICP-MS, Optima 5300DV, Analytik Jena, CO, USA)[24].

\section{Lipid peroxidation and antioxidant profile}

The liver (about $1 \mathrm{~g}$ ) was homogenized using Teflon and pestle homogenizer in ice-cold $0.1 \mathrm{M}$ phosphate buffer saline $\mathrm{pH}$ 7.4. The supernatant was separated after centrifuging the crudehomogenate at $14,000 \mathrm{rpm}$ for 10 $\min$ at $4{ }^{\circ} \mathrm{C}$. Lipid peroxide wasmeasured after the reaction with thiobarbituric acid and expressed as nmol malondialdehyde (MDA) per gram tissue [25]. Griffith method [26] was used to measure the total glutathione and GSSG content.

\section{RNA extraction and qRT-PCR}

About $100 \mathrm{mg}$ hepatic tissues were rinsed in sterilized phosphatebuffer saline and homogenized in liquid nitrogen using Teflon andpestle homogenizer then the homogenates were stored at $-80{ }^{\circ} \mathrm{C}$ till RNA isolation. Total RNA was isolated using the RNeasy Mini Kit(Qiagen $\mathrm{GmbH}$, Germany) according to the manufacturer instructions. cDNA was synthesized from the purified RNA 
using QuantiTect Reverse Transcription Kit (Qiagen). The qRTPCR for the target genes were performed using QuantiTect SYBR Green PCR Master Mix (Qiagen Rotor-Gene Q). The primer sequences of all targetand reference genes and the PCR conditions were recorded in Table 1. The fold change of mRNA expression was calculated after recording the $\mathrm{Ct}$ values for reference and target genes using the $2-\Delta \Delta \mathrm{Ct}$ method.

\section{Statistical analyses}

The distribution of each variable was assessed with the Shapiro-Wilk test, and variance homogeneity among groups was checked with the Levene's test. When parametric assumptions were valid, we used univariate analysis of variance (ANOVA) with Tukey's test as a post-hoc. Otherwise, the nonparametric alternatives (KruskalWallis test and Dunn's post-hoc test) were performed. A probability value 0.05 or less was considered statistically significant. All analyses were performed using the SPSS statistical software package (version 22, IBM Corp., Armonk, NY, USA).

\section{Results and disscussion:}

The results in table (2), (3), and figure (2) indicated significant higher liver content of silver, calcium, GSSG and MDA levels and also, it induces a significant reduction in GSH level, significant down regulation of $\mathrm{Nrf} 2$, PGC- $1 \alpha$ and mTFA in rats treated with AgNPs compared to control rats. Interestingly, the co-supplementation of AgNPs treated rats with LA resulted in significant reduction in the liver content of silver, calcium, GSSG and MDA levels. Moreover, LA results in significant up regulation of Nrf2, PGC$1 \alpha$ and mTFA and also, significant increment in GSH level compared to AgNPs treated rats. Previous studies showed that intraperitoneal injection achieved the highest hepatic tissue (the major organ of detoxification [27]) deposition of AgNPs as compared to other routes of administration [28]. Herein, intraperitoneal injection of AgNPs leads to silver hepatic accomulation initiating hepatotoxicity in rats. It has been generally thought that hepatic nanosilver toxicity is mainly due to the production of ROS in the liver [29]. AgNPs attenuated both active forms of Extracellular regulated kinase (ERK) and protein kinase B (PKB, AKT) protein expression, resulting in suppression of Nrf2 expression, translocation into nucleus, and transcriptional activity and decrease of 8-Oxoguanine DNA glycosylase 1 (OGG1) expression (Nrf2 is an important factor in the inducible regulation of OGG1 [30]) led to increased 8-Oxoguanine (8-oxoG) which is sensitive marker of ROS induced DNA damage. ROS generation from down regulation of Nrf2 and the resultant oxidative stress contribute to the cell damage associated with AgNPs.

Mitochondria are a key regulator of the metabolic activity of the cell, and are also an important organelle in both production and degradation of free radicals [31]. Mitochondrial biogenesis increases metabolic enzymes for glycolysis, oxidative phosphorylation and ultimately a greater mitochondrial metabolic capacity [32], it is highly regulated by nuclear regulatory proteins, mainly NRF1, NRF2 and mTFA (which plays significant roles in mtDNA replication, transcription,structure/organization of the mitochondrial nucleoid [33] and mtDNA packing [34]) [35]. PGC- $1 \alpha$ is a co-transcriptional regulation factor that induces mitochondrial biogenesis by activating different transcription factors, including NRF1, NRF2 which activate mTFA [36]. We can 
summarize that AgNPs toxicity leading to Nrf2 down regulation that consequently increase of ROS generation and oxidative stress cause direct mitochondrial damage, and disturb the function of the respiratory chain [8] alongside with dysfunction in mitochondrial biogenesis owed to down regulation of $\mathrm{PGC} 1 \alpha$ that activate different transcription factors, including NRF1, NRF2 which activate mTFA that has significant roles in mtDNA replication, transcription so mitochondria appear to be the brilliant target for AgNPs. Our results come in harmony with [8] which reported that mitochondria appear to be the sensitive target for AgNPs toxicity. So AgNPs toxicity leading to oxidative DNA damage, oxidations of amino acids in proteins, oxidations of polyunsaturated fatty acids in lipids [6], depletion of glutathione and changes in the activity of several antioxidant enzymes [7]. Exposure to AgNPs induced hepatic calcium overload. As we mentioned before that AgNPs toxicity induced down regulation of $\mathrm{Nrf} 2$ leading to depletion of glutathione that resulted in hypofunction of NMDA receptors [37] and consequently resulted in increasing of calcium overload [38].

On the other hand, LA is an activator of translocation of (Nrf2) to the nucleus for regulation of antioxidant gene expression [18]. LA treatment raised the expression of heme oxygenase 1 (HO-1) and NADPH: quinone oxidoreductase 1(NQO1) which are the two targets of the Nrf2 expression, therefore LA treatment resulted in acceleating the nuclear translocation of $\mathrm{Nrf} 2$ via regulating the Nrf2 signal pathway [39]. Moreover, LA prevented liver oxidative damage through the inhibition of hydroperoxide $(\mathrm{H} 2 \mathrm{O} 2)$ production and the stimulation of mitochondrial antioxidant defenses [40]. LA increases GSH synthesis by reducing cystine to cysteine. Furthermore, LA induces the de novo synthesis of GSH at the transcriptional level by directly modulating cellular signaling pathways. The antioxidant and hepatoprotective effects of LA are restoration of the GSH: GSSG ratio and increased the protein thiol content in the liver [20].[41] approved that LA supplementation significantly reduced MDA. Attractively, we can concluded that LA highly reduced the silver content in the liver indicating its clearance ability via incorporation of sulfhydryl group, upregulated of Nrf2 that inhibit ROS generation resulted in upregulation of PGC- $1 \alpha$ that up regulated mTFA which are responsible for mitochondrial biogenesis, mtDNA trancribtion and replication and also, increases GSH synthesis leading to reduced the $\mathrm{Ca}^{2+}$ content in the liver indicating its protective effect on NMDA receptors. Finally, from previous data we can report that LA protect hepatic cell from damage.

Data in table (4) showed that LA resulted in significant correction in the activities of ALT, AST, and ALP compared to AgNPs treated rats. While, results in table (5) cleared that there was no significant difference in serum total protein, Albumin Globulin, total and direct bilirubin in different groups. However, AgNPs treated group showed decrease in both levels of total protein and albumin while, direct bilirubin concentration was increased but those alterations were not significant as compared to other groups. The previous oxidative stress induced by AgNPs administration consenquently lead to liver damage as ALT, AST and ALP activities were increased, in addition our histopathological findings confirmed this damage as there was focal hepatic necrosis and degeneration of biliary epithelium of bile duct. The variations to the levels of hepatic enzymes 
considered as adaptive mechanisms by the animals trying to equipoise stress enforced by exposure to the AgNPs [42].This result was harmonized with [43] who reported that the dosage of $50 \mathrm{mg} / \mathrm{kg}$ produced significant increaseof AST, ALT and ALP . The potential of AgNPsfor modulation the enzyme activity wasdue to their affinity for thiol groups. Thiol groups in the enzymes made them attractive to the AgNPs leading to formation of complexes.Similarly, [3] showed that intravenous administration of AgNP at $40 \mathrm{mg} / \mathrm{kg}$ in Wistar rats exhibited significant increase in the levels of ALT, AST, ALP, GGT and total bilirubin [22]. [44] showed that the rate of total bilirubin had no significant change. On the other hand, coadministration of LA inhibited the development of liver injury, as indicated by reductions of liver function enzymes [45] and this came in harmony with our histopathological findings that mentioned improvement of hepatic lesion as compared with nanosilver group.

Results in table (6) cleared that in compared to control values, AgNPs induced a significant reduction in HDL-c level alongside with a significant increment in Total cholesterol, LDL-c and TG levels. Compared to AgNPs group, coadministration of LA showed lipid lowering activity as there was significant rise in HDL-c level along with the reduction of Total cholesterol, TG and LDL-c. Silver nanoparticles administration had a negative effect on serum lipid profile. Similarly, [46] showed that administration of an aqueous solution of silver nanoparticles to chickens causing an increase in total cholesterol, TG and LDL-c due to hepatocellular damage. On the other hand, co-treatment with LA elevated serum HDL-c level and decreased levels of total cholesterol, LDL-c, TG and VLDL-c. This result come in agreement with [47] who showed that LA has the ability to reduced bad cholesterol (LDL-c), total cholesterol and T.G and elevated serum good cholesterol (HDL-c) as increased the activity of lipoprotein lipase, promoted fat oxidation and prevented its accumulation in visceral tissues.

\section{Conclussion}

In conclusion, AgNPs $(50 \mathrm{mg} / \mathrm{kg})$ intraperitoneal administration could induce hepatotoxicity, oxidative stress, necrosis substantial decrease in cell viability with concomitant increases in DNA damage, because of perturbation hepatocellular membrane, reduction of antioxidant defense, and initiation of down-regulation of Nrf2, PGC- $1 \alpha$ and mTFA. On the other hand, cotreatment with LA $(100 \mathrm{mg} / \mathrm{kg})$ improved the previous alterations and showed promising hepatoprotective and antioxidant properities.

\section{References:}

1. JinKang, S.; Ryoo, I.; Lee, Y.J.; Kwak, M. (2012). Role of the Nrf2-heme oxygenase1 pathway in silver nanoparticle-mediated cytotoxicity, Toxico. Appli. Pharmac. 258: 89-98.

2. Loeschner, K.; Hadrup, N.; Qvortrup, K.; Larsen, A.; Gao, X.; Vogel, U.; Mortensen, A.; Lam, H.R.;Larsen, E.H. (2011). Distribution of silver in rats following 28 days of repeated oral exposure to silver nanoparticles or silver acetate. Part Fibre Toxicol. 8:18.

3. Wen, H.; Dan, M.; Yang, Y.; Lyu, J.; Shao, A.; Cheng, X.; Chen, L.; Xu, L. (2017). Acute toxicity and genotoxicity of silver 
nanoparticle in rats. PLoS ONE. 12(9): 1-16.

4. Lee, Y.Z.; Liu, S.M.; Huang, J.L.; Lue, I.S.; Lin, C.L.; Kwan, L.A.; and Cheng, R. (2013). Bioenergetic failure correlates with autophagy and apoptosis in rat liver following silver nanoparticle intraperitoneal administration. Particle and Fibre Toxicology. 10:40.

5. Choi, J.E.; Kim S.; Ahn J.H.;Youn P.; Kang J.S.; Park, K. (2010). Induction of oxidative stress and apoptosis by silver nanoparticles in the liver of adult zebrafish. AquatToxicol. 100. (2): 151-159.

6. Li, J.J.; Hartono, D.; Ong, C-N.; Bay, B-H.; Yung, L-YL.(2010). Autophagy and oxidative stress associated with gold nanoparticles. Biomaterials. 31(23): 5996-6003.

7. Van Aerle, R.; Lange, A.; Moorhouse, A.; Paszkiewicz, K.; Ball, K.; Johnston, B.D.; deBastos, E.; Booth, T.; Tyler, C.R.;Santos, E.M. (2013). Molecular Mechanisms of Toxicity of Silver Nanoparticles in Zebrafish Embryos. Environ Sci Technol.47:8005-8014.

8. Bressan, E.; Vindigni, V.; Ferroni, L.; Cairns, W.; Gardin, C.; Rigo, C.; Zavan, B.; Stocchero, M. (2013). Silver Nanoparticles and Mitochondrial Interaction. Int J Dentistry. 2013:1-8.

9. Aquilano, K.; Vigilanzam, P.; Baldelli, S.; Pagliei, B.; Rotilio, G.; Ciriolo, M.R.(2010). Peroxisome proliferator-activated receptor gamma co-activator 1alpha (PGC-1alpha) and sirtuin 1 (SIRT1) reside in mitochondria: possible direct function in mitochondrial biogenesis. J Biol Chem. 285:21590-21599.

10. Aquilano, K.; Baldelli, S.; Pagliei, B.; Ciriolo, M.R. (2013). Extranuclear localization of SIRT1 and PGC-1alpha: an insight into possible roles in diseases associated with mitochondrial dysfunction. CurrMol Med. 13:140-154.

11. Garstka, H.L.; Schmitt, W.E.; Schultz, J. (2003). Import of mitochondrial transcription factor A (TFAM) into rat liver mitochondria stimulates transcription of mitochondrial DNA. Nucleic Acids Res. 31:5039-5047.

12. Ekstrand, M.I.; Falkenberg, M.; Rantanen, A. (2004). Mitochondrial transcription factor A regulates mtDNA copy number in mammals. Hum Mol Genet. 13:935-944.

13. Suliman, H.B.; Carraway, M.S.; Piantadosi, C.A. (2003). Postlipopolysaccharide oxidative damage of mitochondrial DNA. Am J RespirCrit Care Med. 167:570-579.

14. Uskoković, A.; Dinić, S.; Jovanović, A.J.; Poznanović, G.; Vidaković, M.; and Mihailović, M. (2017). Liver Diseases: Epigenetic Mechanisms, Oxidative Stress and Use of Alpha-Lipoic Acid. Handbook of Nutrition, Diet, and Epigenetics pp 1-21. 
15. Tanaka, Y.; Kaibori, M.; Miki, H.; Nakatake, R.; Tokuhara, K.; Nishizawa, M.; Okumura, T.; and Kwon, A. (2015). Alphalipoic acid exerts a liver-protective effect in acute liver injury rats. Journal of surgical research. $193.675-683$.

16. Ambrosi, N.;Guerrieri, D.; Caro, F.; Sanchez, F., Casadei, D., Incardona, C., and Chuluyan, E. (2018). Alpha Lipoic Acid: A Therapeutic Strategy that Tend to Limit the Action of Free Radicals in TransplantationInt $\mathrm{J}$ Mol Sci.19(1): 102.

17. Golbidi, S., Badran, M., Laher, I. (2011). Diabetes and alpha lipoic Acid. Front Pharmacol. 2:69.

18. Gomes BM and Negrato AC. (2014). Alpha-lipoic acid as a pleiotropic compound with potential therapeutic use in diabetes and other chronic diseases. DiabetolMetabSyndr. 2014 (6): 80.

19. Li, W.; Khor, T.O.; Xu, C., Shen, G., Jeong, W.S.; Yu, S.; Kong, A.N. (2008). Activation of Nrf2antioxidant signaling attenuates $\mathrm{NF}-\kappa \mathrm{B}$-inflammatory response and elicits apoptosis. BiochemPharmacol.76 (11):14851489.

20. Dinić, S., Arambašić, J.; Mihailović, M.; Uskoković, A.; Grdović, N.; Marković, J.; Karadžić, B.; Poznanović, G.; Vidaković, M. (2013). Decreased O-GlcNAcylation of the key proteins in kinase and redox signalling pathways is a novel mechanism of the beneficial effect of $\alpha$-lipoic acid in diabetic liver. $\mathrm{Br}$ J Nutr. 110:401-4012.

21. Li, X.; Xu, L.; Shao, A.; Wu, G.; Hanagata, N. (2013). Cytotoxic and genotoxic effects of silver nanoparticles on primary Syrian hamster embryo (SHE) cells, J. Nanosci.Nanotechnol. 13: 161170.

22. Tiwari, D.K.; Jin, T.; Behari, J. (2011). Dose-dependent in-vivo toxicity assessment of silver nanoparticle in Wistarrats. Toxicology mechanisms and methods. 21(1):13-24.

23. Pari, L.; Murugavel, P. (2004). Protective effect of alpha-lipoic acid against chloroquineinduced hepatotoxicity in rats, J. Appl. Toxicol. 24: 21-26.

24. Yan, L.; Y.L.; Guoxjx, J.; Ma, X.; Yan, Q. (2013). Comparison of dry ashing, Wet ashing and microwave digestion for determination of trace elements in periostracum serpentis and periostracum cicade by ICP-AES. J. Chil. Chem. Soc. 58: ISSN 07179707.

25. Ohkawa, H.; Ohishi N.; Yagi, K. (1979). Assay for lipid peroxides in animal tissues by thiobarbituric acid reaction, Anal. Biochem. 95: 351-358.

26. Griffith, O.W. (1980). Determination of glutathione and glutathione disulfide using glutathione reductase and 2-vinyl pyridine. Anal Biochem. 106: 2072012

27. Xue, Y.; Zhang, S.; Huang, Y.; Zhang, T.; Liu, X.; Hu, Y.; Zhang, Z.; Tang, M. (2012). 
Acute toxic effects and genderrelated biokinetics of silver nanoparticles following an intravenous injection in mice. $\mathrm{J}$ ApplToxicol. 32:890-899.

28. Katsnelson, B.A.; Privalova, L.I.; Gurvich, V.B.; Makeyev, O.H. (2013). Comparative in vivo assessment of some adverse bioeffects of equidimensional gold and silver nanoparticles and the attenuation of nanosilver's effects with a complex of innocuous bioprotectors.". Int J Mol Sci. 14: 2449-2483

29. Zhu，L.; Guo，D.; Sun, L.; Huang, Z.; Zhang.; X, M.; Xiao, L.; Zhao, Y.; Gu, N. (2017). Activation of autophagy by elevated reactive oxygen species rather than released silver ions promotes cytotoxicity of polyvinylpyrrolidone-coated silver nanoparticles in hematopoietic cells. Nanoscale. 9: 5489-5498.

30. Piao, M.J.; Kim, K.C.; Choi, J.Y.; Choi, J.; Hyun, J.W. (2011). Silver nanoparticles down-regulate Nrf2-mediated 8-oxoguanine DNA glycosylase 1 through inactivation of extracellular regulated kinase and protein kinase $\mathrm{B}$ in human Chang liver cells. Toxicol Lett. 207:143-149.

31. Bevilacqua, L.; Ramsey J.J.; Hagopian, K.; Weindruch, R.; Harper, M.E. (2004). "Effects of short- and medium-term calorie restriction on muscle mitochondrial proton leak and reactive oxygen species production". American Journal of Physiology.
Endocrinology and Metabolism. 286 (5): 852-861.

32. Mishra, P.; Chan D.C. (2016). "Metabolic regulation of mitochondrial dynamics". The Journal of Cell Biology. 212 (4): 379-387.

33. Canugovi, C.; Scott Maynard, S.; Bayne, A.V.; Sykora, P.; Tian, J.; Souza-Pinto, NC.; Croteau, D.L.; and Vilhelm, A.; Bohr, V.A. (2010). The Mitocondrial transcription factor A function in mitochondrial baseexcision repair. DNA Repair (Amst). 9(10): 10801089.

34. Bin, L.U.; Lee, J.; Nie, X.; Li, M. (2013). Phosphorylation of human TFAM in mitochondria impairs DNA binding and promotes degradation by the AAA+ Lon protease. Mol Cell. 49: 121-132.

35. Carvalho, C.; Santos M.S.; Oliveira, C.R.; Moreira, P.I. ( 2015). Alzheimer's disease and type 2 diabetes-related alterations in brain mitochondria, autophagy and synaptic markers. Biochimica et Biophysica Acta. 1852:16651675.

36. Jornayvaz, F.; and Shulman, G.I. (2010). Regulation of mitochondrial biogenesis Essays Biochem. 47(10). 69:84

37. Steullet, P.; Neijt, H.C.; Cuénod, M.; Do, K.Q. (2006). "Synaptic plasticity impairment and hypofunction of NMDA receptors induced by glutathione deficit: Relevance to schizophrenia". Neuroscience. 137 (3): 807-19. 
38. Ziemi'nska, E.; Stafiej, A.; Stru'zy'nska, L. (2014). The role of the glutamatergic NMDA receptor in nanosilver-evoked neurotoxicity in primary cultures of cerebellar granule cells. Toxicology 315 (6) 38- 48.

39. Cheng, Y.; Luo, F.; Zhang, Q.; Sang, Y.; Chen, X.; Zhang, L.; Liu, Y.; Li, X.; Li, J.; Ding, H.; and Mei, Y. (2018). a-Lipoic acid alleviates pentetrazol-induced neurological deficits and behavioral dysfunction in rats with seizures via an Nrf2 pathway. RSC Adv. 8: 4084.

40. Valdecantos, M.P.; PérezMatute, P.; González-Muniesa, P.; Prieto-Hontoria,

P.L.; Moreno-Aliaga,

M.J.; Martínez, J.A. (2012). Lipoic acid improves mitochondrial function in nonalcoholic steatosis through the stimulation of sirtuin 1 and sirtuin 3. Obesity (Silver Spring). 20(10):1974-1983.

41. Vidović, B.; Milovanović, S.; Dorđević, $\quad$ B.; $\quad$ KoturStevuljević, J. (2014). Effect of alpha-lipoic acid supplementation on oxidative stress markers and antioxidative defense in patients with schizophrenia. Psychiatr Danub. 26: 205-213.

42. Adeyemi, O.S.; and Adewumi, I. (2014). Biochemical Evaluation of Silver Nanoparticles in Wistar Rats. Hindawi. 2014: 196091.
43. Hawkins, B.T.; Davis, T.P. (2005). The blood-brain barrier/neurovascular unit in health and disease, Pharmacol. Rev.2005; 57: 173-185.

44. Najjaran, A.; Moghaddam, N.A.; Zarchi, S.R.; Mohsenifar, J.; Rasoolzadeh, R. (2014). Toxicity effects of nanosilver on liver enzymes, liver and lung tissues. (IJBES). 1(1) 1-5.

45. AL Abdan, M. (2012). AlfaLipoic Acid Controls Tumor Growth and Modulates Hepatic Redox State in Ehrlich-AscitesCarcinoma-Bearing Mice. Scien.Worl.Jour. 2012: 509838.

46. Czech, A.; Ognik, K.; Cholewińska, E.; Kozłowski, K.; Wlazło, L. (2016). Effect of silver nanoparticles on the immune, redox, and lipid status of chicken blood CJAS R. Szlązak and K. Tutaj were supported by the Foundation for Polish Science (Project "Molecular Spectroscopy for Bio Medical Studies" under the TEAM programme. 61: 450-46.

47. AL-Ghamdi, A.M.; Choudhry, H.; AL-Doghather, A.H.; Huwait, H.E.; Kumosani, A.T.; and Moselhy, S.S. (2017). Potential Adminstration OF Lipoic acid and coenzyme $Q$ against adipogenesis:target for weight reduction. Afr $\mathrm{J}$ Tradit Complement Altern Med. 14(1):272-27. 
Table 1: Primer sequences used for qRT-PCR. PGC1- $\alpha$ (Peroxisome proliferator activator receptor gamma-coactivator $1 \alpha)$, mitochondrial transcription factor A (mTFA) and Nrf2 (nuclear factor erythroid 2-related factor)

\begin{tabular}{||l|l|l||}
\hline \multirow{2}{*}{ Gene } & \multicolumn{2}{|l|}{ primer sequence } \\
\hline \multirow{3}{*}{ Mtfa } & F: & 5'-AAACTTGCTAGCGGTCCTCA-3' \\
\cline { 2 - 4 } & R: & 5'-TGGCTGGTGCCAGTAAGAG-3' \\
\hline \hline \multirow{3}{*}{ Nrf2 } & F: & 5'CCCTGGAAGCTTTCAGATACG-3' \\
\cline { 2 - 4 } & R: & 5'-AATTGCAGCCATGTGGAGG-3' \\
\hline \hline \multirow{3}{*}{ GAPDH } & F: & 5'-TCTCCTCGCTGGAAAAAGAA-3' \\
\cline { 2 - 4 } & R: & 5'-TCTCCTCGCTGGAAAAAGAA-3' \\
\hline \hline
\end{tabular}

Table 2: Effect of alph-lipolic acid on hepatic trace element concentrations of nano silver treated albino rats

\begin{tabular}{lllll}
\hline \multirow{4}{*}{ Group } & \multicolumn{3}{l}{ Parameter } & \\
\cline { 2 - 5 } & Ag+ $(\mathrm{ppm})$ & $\begin{array}{l}\mathrm{Ca}+2 \\
(\mathrm{ppm})\end{array}$ & $\begin{array}{l}\mathrm{Cu}+2 \\
(\mathrm{ppm})\end{array}$ & $\begin{array}{l}\mathrm{Zn}+2(\mathrm{ppm}) \\
\mathrm{Fe}+2(\mathrm{ppm})\end{array}$ \\
\hline Control & & $37.0 \pm$ & $2.37 \pm$ & $6.79 \pm 0.81^{\mathrm{a}}$ \\
Ag-NPs & & $3.10^{\mathrm{b}}$ & $0.41^{\mathrm{a}}$ & $40.5 \pm 4.72^{\mathrm{a}}$ \\
Ag-NPs + LA & $0.06 \pm 0.02^{\mathrm{b}}$ & $61.1 \pm$ & $2.38 \pm$ & $6.30 \pm 0.62^{\mathrm{a}}$ \\
& $8.43 \pm 1.46^{\mathrm{a}}$ & $4.62^{\mathrm{a}}$ & $0.38^{\mathrm{a}}$ & $35.4 \pm 4.70^{\mathrm{a}}$ \\
& $0.38 \pm 0.10^{\mathrm{b}}$ & $41.7 \pm$ & $2.52 \pm$ & $5.92 \pm 0.04^{\mathrm{a}}$ \\
& & $3.87^{\mathrm{b}}$ & $0.61^{\mathrm{a}}$ & $36.8 \pm 2.17^{\mathrm{a}}$ \\
\hline
\end{tabular}

Ag-NPs, Nanosilver particles; LA, $\alpha$-lipoic acid. Values are means \pm standard errors.

Means without a common superscript in a column differ significantly $(\mathrm{P} \leq 0.05)$. 
Table 3: Effect of alph-lipolic acid on hepatic measures of oxidative stress of nano silver treated albino

\begin{tabular}{|c|c|c|c|c|}
\hline \multirow[b]{2}{*}{ Group } & \multicolumn{4}{|l|}{ Parameter } \\
\hline & $\begin{array}{l}\text { Total GSH } \\
\text { ( } \mu \mathrm{mol} / \mathrm{g} \text { tissue })\end{array}$ & $\begin{array}{l}\text { Total GSH } \\
(\mu \mathrm{mol} / \mathrm{g} \text { tissue })\end{array}$ & $\begin{array}{l}\text { GSH } \\
(\mu \mathrm{mol} / \mathrm{g} \text { tissue })\end{array}$ & $\begin{array}{l}\text { GSH to } \\
\text { GSSG } \\
\text { Ratio }\end{array}$ \\
\hline Control & $1.92 \pm 0.07^{\mathrm{a}}$ & $1.92 \pm 0.07^{\mathrm{a}}$ & $1.71 \pm 0.06^{\mathrm{a}}$ & $16.8 \pm 1.25^{\mathrm{a}}$ \\
\hline Ag-NPs & $1.12 \pm 0.03^{b}$ & $1.12 \pm 0.03^{b}$ & $0.73 \pm 0.04^{\mathrm{c}}$ & $3.75 \pm 0.32^{\mathrm{c}}$ \\
\hline Ag-NPs + LA & $1.47 \pm 0.10^{\mathrm{a}}$ & $1.47 \pm 0.10^{\mathrm{a}}$ & $1.20 \pm 0.09^{b}$ & $8.92 \pm 0.75^{\mathrm{b}}$ \\
\hline
\end{tabular}

$\overline{\text { Ag-NPs, Nanosilver particles; LA, } \alpha \text {-lipoic acid; GSSG, oxidized glutathione; GSH, reduced }}$ glutathione; MDA, malondialdhyde.

Values are means \pm standard errors. Means without a common superscript in a column differ significantly $(\mathrm{P} \leq 0.05)$.

Table 4: Effect Effect of Alph-lipolic acid on liver enzyme activities of nano silver treated albino rats

Parameter

\begin{tabular}{lllll} 
Group & ALP (U/l) & AST (U/l) & ALT (U/l) & $\begin{array}{l}\text { AST to ALT } \\
\text { ratio }\end{array}$ \\
\hline Control & & & & \\
Ag-NPs & $171 \pm 9.80^{\mathrm{b}}$ & $172 \pm 7.08^{\mathrm{b}}$ & $55.8 \pm 4.12^{\mathrm{b}}$ & $3.84 \pm 0.36^{\mathrm{a}}$ \\
Ag-NPs + LA & $263 \pm 9.38^{\mathrm{a}}$ & $253 \pm 7.61^{\mathrm{a}}$ & $80.2 \pm 5.54^{\mathrm{a}}$ & $3.20 \pm 0.16^{\mathrm{a}}$ \\
& $201 \pm 16.02^{\mathrm{b}}$ & $209 \pm 8.03^{\mathrm{b}}$ & $54.0 \pm 2.88^{\mathrm{b}}$ & $3.21 \pm 0.20^{\mathrm{a}}$
\end{tabular}

Ag-NPs, Nanosilver particles; LA, $\alpha$-lipoic acid. Values are means \pm standard errors...Means without a common superscript in a column differ significantly $(\mathrm{P} \leq 0.05)$.

Table 5: Effect of alph-lipolic acid on serum protein and bilirubin levels of nano silver treated albino rats.

\begin{tabular}{llllll}
\hline \multirow{5}{*}{ Group } & $\begin{array}{l}\text { Parameter } \\
\text { protein } \\
(\mathrm{g} / \mathrm{dl})\end{array}$ & $\begin{array}{l}\text { Albumin } \\
(\mathrm{g} / \mathrm{dl})\end{array}$ & $\begin{array}{l}\text { Globulin } \\
(\mathrm{g} / \mathrm{dl})\end{array}$ & $\begin{array}{l}\text { Albumin to globulin ratio } \\
\text { bilirubin }(\mathrm{mg} / \mathrm{dl})\end{array}$ & Direct \\
\hline Control & $7.60 \pm$ & $4.26 \pm$ & $3.34 \pm$ & $1.28 \pm 0.02^{\mathrm{a}}$ & $0.02 \pm$ \\
Ag-NPs & $0.29^{\mathrm{a}}$ & $0.16^{\mathrm{a}}$ & $0.14^{\mathrm{a}}$ & $0.004^{\mathrm{a}}$ & $0.05 \pm$ \\
Ag-NPs & $7.34 \pm$ & $3.88 \pm$ & $3.46 \pm$ & $1.14 \pm 0.09^{\mathrm{a}}$ & $0.03 \pm$ \\
+ LA & $0.25^{\mathrm{a}}$ & $0.16^{\mathrm{a}}$ & $0.21^{\mathrm{a}}$ & $0.016^{\mathrm{a}}$ & \\
& $7.52 \pm$ & $4.10 \pm$ & $3.42 \pm$ & $1.26 \pm 0.15^{\mathrm{a}}$ & \\
& $0.29^{\mathrm{a}}$ & $0.16^{\mathrm{a}}$ & $0.34^{\mathrm{a}}$ & $0.006^{\mathrm{a}}$ & \\
& & & & &
\end{tabular}

Ag-NPs, Nanosilver particles; LA, $\alpha$-lipoic acid. Values are means \pm standard errors. Means without a common superscript in a column differ significantly $(\mathrm{P} \leq 0.05)$. 
Table 6: Effect of alph-lipolic acid and on serum lipid profile of nano silver treated albino rats

\begin{tabular}{llllll}
\hline & \multicolumn{3}{l}{ Parameter } & & \\
\cline { 2 - 5 } Group & TG $(\mathrm{mg} / \mathrm{dl})$ & $\begin{array}{l}\text { Total } \\
\text { cholesterol } \\
(\mathrm{mg} / \mathrm{dl})\end{array}$ & $\begin{array}{l}\text { HDL } \\
(\mathrm{mg} / \mathrm{dl})\end{array}$ & vLDL $(\mathrm{mg} / \mathrm{dl})$ & LDL $(\mathrm{mg} / \mathrm{dl})$ \\
\hline Control & $67.2 \pm$ & $76.6 \pm$ & $45.6 \pm$ & $13.4 \pm 0.39^{\mathrm{c}}$ & $17.6 \pm 2.96^{\mathrm{b}}$ \\
Ag-NPs & $1.93^{\mathrm{c}}$ & $3.26^{\mathrm{b}}$ & $2.16^{\mathrm{a}}$ & $22.4 \pm 1.17^{\mathrm{a}}$ & $41.6 \pm 4.73^{\mathrm{a}}$ \\
Ag-NPs & $112 \pm 5.87^{\mathrm{a}}$ & $97.3 \pm$ & $33.4 \pm$ & $16.8 \pm 0.67^{\mathrm{b}}$ & $15.4 \pm 2.21^{\mathrm{b}}$ \\
+ LA & $84.0 \pm$ & $4.05^{\mathrm{a}}$ & $2.85^{\mathrm{b}}$ & & \\
& $3.36^{\mathrm{b}}$ & $76.9 \pm$ & $44.7 \pm$ & & \\
& & $3.73^{\mathrm{b}}$ & $3.23^{\mathrm{a}}$ & & \\
\end{tabular}

Ag-NPs, Nanosilver particles; LA, $\alpha$-lipoicacid;TG, Triglycerides; HDL, High density lipoprotein cholesterol; vLDL, very low density lipoprotein cholesterol; LDL, low density lipoprotein cholesterol. Values are means \pm standard errors. Means without a common superscript in a column differ significantly $(\mathrm{P} \leq 0.05)$.

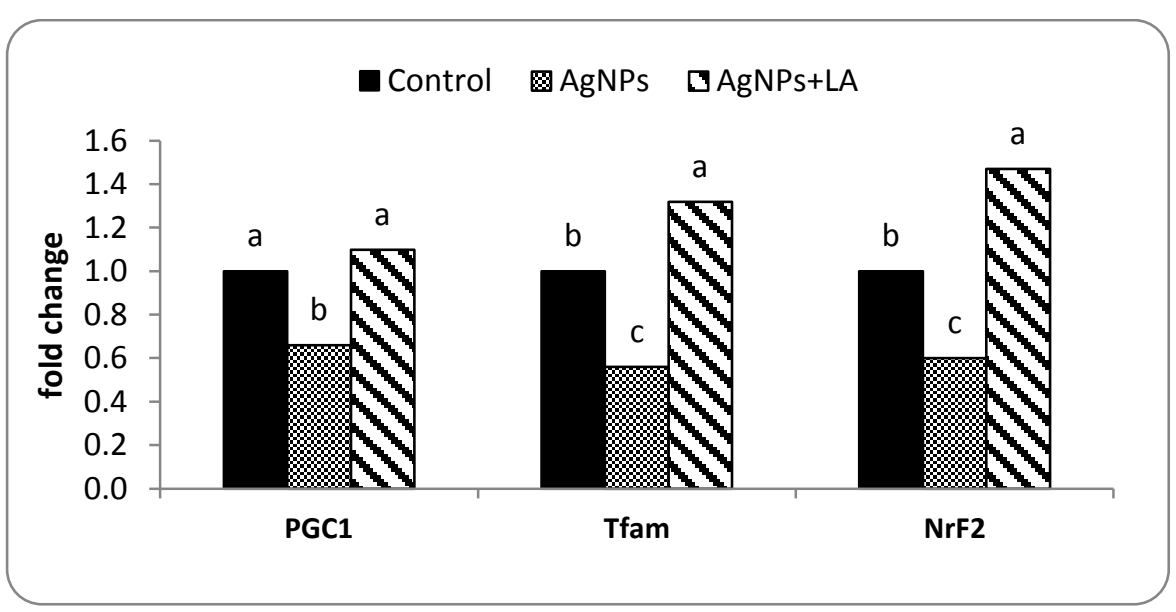

(Figure 2) Effect of alph-lipolic acid on genes of nano silver treated albino rats Ag-NPs, Nanosilver particles; LA, $\alpha$-lipoic acid; PGC1- $\alpha$ (Peroxisome proliferator activator receptor gamma-coactivator $1 \alpha$ ), mitochondrial transcription factor A (mTFA) and Nrf2 (nuclear factor erythroid 2-related factor)

Values are means \pm standard errors. Means without a common superscript in a column 